Revista lus et Praxis, Año 24, No 2, 2018, pp. 393 - 430

ISSN 0717 - 2877

Universidad de Talca - Facultad de Ciencias Jurídicas y Sociales

La interpretación constitucional y sus métodos en el sistema jurídico norteamericano

Walter Arévalo - Luisa García

Trabajo recibido el 18 de octubre de 2016 y aprobado el 12 de diciembre de 2017

\title{
La interpretación constitucional y sus métodos en el sistema jurídico norteamericano, una interacción entre lo político y lo jurídico: Teorías y casos de estudio
}

\section{CONSTITUTIONAL INTERPRETATION AND ITS METHODS IN THE AMERICAN LEGAL SYSTEM, AN INTERACTION BETWEEN LAW AND POLITICS: THEORIES AND CASE LAW*}

\author{
Walter Arévalo Ramírez \\ LUISA FERNANDA GarCía LÓPEZ ${ }^{* * *}$
}

\begin{abstract}
RESUMEN
Buscando presentar un aporte novedoso al estudio de los métodos de interpretación que se aplican en los sistemas constitucionales de los cuales hemos importado instituciones en el mundo del derecho continental en Latinoamérica, el presente artículo busca ofrecer, ante la escasa literatura en castellano, un estudio introductorio a los métodos de interpretación constitucional en el sistema jurídico norteamericano, especialmente el originalismo, el no-originalismo y el constitucionalismo viviente, desarrollando su relación con el derecho de precedente, explicando las distintas naturalezas jurídico-políticas de los métodos, su fundamentación histórica, sus procedimientos específicos y el impacto que tienen en el resultado de la actividad del juez constitucional. El documento presenta primero una descripción teórica de los métodos desde la teoría constitucional norteamericana, y luego desarrolla su aplicación práctica a través del caso District of Columbia v. Heller de la Corte Suprema de Estados Unidos.
\end{abstract}

ABSTRACT

Seeking to provide a contribution to the study of the methods of interpretation that apply in the constitutional systems from which we have imported and transplanted institutions to the world

* El presente artículo forma parte de las investigaciones de los autores en el contexto de las líneas de investigación "confluencias entre derecho público y derecho privado" y "El derecho internacional a la luz de los diferentes tribunales internacionales y nacionales" de los grupos de investigación en derecho privado y derecho internacional de la Facultad de Jurisprudencia de la Universidad del Rosario y la tesis doctoral en derecho internacional y tribunales constitucionales.

** Profesor de Carrera Académica de Derecho Internacional, Universidad del Rosario. Abogado - Politólogo con Especialización en Derecho Constitucional. LL.M. (Master of Laws) en International Law and Legal Studies, Stetson University College of Law. Phd(cd) y Miembro del Grupo de Investigación de Derecho Internacional. Facultad de Jurisprudencia Universidad del Rosario. Email: HYPERLINK “mailto:walter.arevalo@urosario.edu.co" walter.arevalo@urosario.edu.co.

*** Profesora Principal de derecho constitucional y constitucional comparado. Grupo de Derecho Privado. Facultad de Jurisprudencia de la Universidad del Rosario. Abogada de la Universidad del Rosario con Maestría en Derecho Internacional Público, Maestría en Derecho Público General y Doctorado en Derecho de la Universidad de Montpellier. Email: Luisa.garcia@urosario.edu.co. 
of civil law in Latin America, this article seeks to provide, in presence of the scarce literature in Spanish about this topic, an introductory study of the methods of constitutional interpretation in the American legal system, especially originalism, non-originalism and living constitutionalism: developing their relationship with the notions of case-law and precedent, explaining the different legal and political implications of such methods, its historical foundations, its legal nature, their specific procedures, and their impact in the rulings and the activity of the Supreme Court. The paper first presents a theoretical description of the methods from the perspective of the American constitutional theory, and then develops its practical application through the case of District of Columbia vs. Heller Supreme Court of the United States.

\section{Palabras Clave}

Interpretación constitucional, constitucionalismo viviente, derecho norteamericano

KEY WORDS

Constitutional interpretation, living constitucionalism, american legal system

\section{Introducción}

Con el auge del nuevo constitucionalismo, los puntos de contacto entre distintas tradiciones constitucionales cada vez son más relevantes y son constante objeto de estudio desde los más diversos enfoques ${ }^{1}$, como la historia y teoría constitucional, la teoría del derecho, el derecho comparado, la teoría de la decisión judicial y la teoría del Estado.

Temáticas tan amplias como la supremacía de la constitución en distintos sistemas jurídicos ${ }^{2}$, la noción de precedente y su incorporación a sistemas de derecho civil gracias a la recepción de tradiciones constitucionales de otras latitudes ${ }^{3}$, los trasplantes jurídicos en el nivel constitucional, la relación entre derechos fundamentales y constitución ${ }^{4}$, la popularidad de la ponderación, el auge del garantismo constitucional o las distintas manifestaciones de modelo de control constitucional han sido objeto de profundos estudios tanto en América como en Europa.

En el contexto de esos grandes y benéficos encuentros de tradiciones y mentalidades, que han permitido novedosos desarrollos en las jurisdicciones constitucionales de todo el mundo, resulta especialmente curiosa la escasez de estudios sobre los métodos de interpretación del texto constitucional construidos y aplicados por otras tradiciones jurídicas distintas a la local, métodos que ayudarían a entender mucho mejor las prácticas constitucionales que se han importado de estas últimas.

${ }^{1}$ Carbonell (2003), pp. 15-29.

2 García de Enterria (1985).

${ }^{3}$ Medina (2004), pp. 1-61.

${ }^{4}$ Alexy (2009), pp. 44-93. 
Hoy, prácticas como el precedente jurisprudencial, las sentencias estructurales, los test de escrutinio y la ponderación ${ }^{5}$, la interpretación no textual de los derechos y muchas otras herramientas que son resultado del encuentro de culturas constitucionales, no pueden entenderse plenamente si no se tiene en mente el modelo de interpretación constitucional vigente en la tradición constitucional de la cual provienen, si se asumen como trasplantes perfectos, o sin contemplar la comparación de los métodos de interpretación de las tradiciones constitucionales involucradas en su desarrollo, y si no se reconocen y entienden los productos del nuevo constitucionalismo como fenómenos híbridos del derecho.

Las distancias entre las fuentes de estos híbridos y los métodos de interpretación originarios de su lugar de procedencia pueden ser inmensas, lo que hace el estudio de sus raíces cada vez más necesario.

Como ejemplo de estas distancias, podemos mencionar como, en el caso del constitucionalismo francés, la teoría predominante, la teoría realista de la interpretación corresponde a una visión distinta de las que ofrecen los modelos de interpretación norteamericanos, en la medida en que el modelo francés ${ }^{6}$ no concibe a la norma de derecho como sujeta a una posible interpretación que pueda ser casuística en lo político, temporal o social, ya que aquella por definición, en tanto "norma", debe ser determinada y concreta. Por lo tanto, para el realismo francés, a diferencia de los modelos americanos más liberales, las normas jurídicas no cambian según demanda la realidad, y solo lo hacen si son modificadas mediante otra norma de la misma naturaleza (proceso formal en manos del constituyente derivado $)^{7}$.

Estas relaciones, semejanzas y diferencias entre sistemas que se han heredado o prestado instituciones, indican que la idea de concebir la constitución como cambiante o viva, se concibe en el marco de una teoría que acepte que los textos constitucionales encierran un significado ambiguo e indeterminado, susceptible de ser expandido mediante la interpretación (como es el caso norteamericano), pero que también tiene recibo, en distintos niveles, en otras tradiciones constitucionales.

Autores como Hesse explican detalladamente cómo otros sistemas constitucionales distintos al norteamericano y de corte europeo han desarrollado sus propios modelos conceptuales de interpretación constitucional para admitir que el ámbito político de la constitución permita que, para la realización de la misma (como la voluntad de que la constitución cada día se moldee para responder efectivamente a la conducta humana, expresado por Hesse bajo el concepto de Wille

\footnotetext{
${ }^{5}$ Alexy (2003), pp. 433-449.

${ }^{6}$ Pactet (1992), pp. 503-515; РАстет (1998), pp. 279-295.

7 Pfersmann (2009).
} 
zu Verfassung) ${ }^{8}$, se pueda invocar a los cambios sociales para reinterpretar su contenido textual sin implicar una enmienda formal (descrito por Hesse en este modelo europeo como Verfassungwandel o mutación de la constitución).

Para el propósito de encaminarse en el estudio de los métodos de interpretación que se aplican en los sistemas constitucionales de los cuales hemos importado instituciones en el mundo del derecho continental en Latinoamérica, el presente artículo busca ofrecer, ante su escasa literatura en castellano, un estudio introductorio a los métodos de interpretación constitucional en el sistema jurídico norteamericano y su relación con el derecho de precedente, explicando las distintas naturalezas jurídico-políticas de los métodos, su fundamentación histórica, sus procedimientos específicos y el impacto que tienen en el resultado de la actividad del juez constitucional.

\section{La dimensión política de los métodos de interpretación constitucional norteamericanos como premisa analítica: interpretación, democracia y cambio social}

Antes de estudiar el método y la filosofía detrás de cada método de interpretación en el sistema norteamericano, es importante versar sobre su relación con el ejercicio democrático. Stephen Breyer, Associate Justice de la Corte Suprema de EE.UU., en su obra sobre la relación de control entre poderes públicos en el sistema norteamericano, explica que en gran medida los métodos de interpretación jurídica tienen un origen en la distribución del poder soberano de la nación hacia los ciudadanos y son en sí mismos un ejercicio de la libertad como principio del sistema jurídico, pues son ejercidos por ciudadanos (jueces, litigantes) que terminan siendo parte del sistema. Esa relación de participación en el entendimiento de las normas escritas, que involucra a los ciudadanos día a día y que correlaciona en el ejercicio del derecho al pueblo y sus gobernantes se llama la libertad activa, y es a su vez, una invitación abierta a la ciudadanía a interpretar su propia constitución ${ }^{9}$. De acuerdo con la libertad activa, las instituciones y métodos de interpretación deben concebirse para ser durables como instituciones doctrinales, pero a la vez, ser capaces de traducir la voluntad del pueblo, que es cambiante según las circunstancias del momento, a través de sus políticas y sus decisiones judiciales.

La justificación de la democratización de los métodos de interpretación implica varios debates sobre las Ilamadas "evoluciones jurídicas", como aquellas

\footnotetext{
${ }^{8}$ Hesse (1992), pp.19-25.

${ }^{9}$ BREYER (2005), pp. 151-178.
} 
ocasiones en que instituciones tradicionales se ven forzadas al cambio por las evoluciones y demandas sociales.

La concepción liberal norteamericana de las instituciones jurídicas evolucionables considera que permitirle a la interpretación jurídica modificar antiguas nociones del derecho según las demandas sociales es un objetivo democrático ${ }^{10}$. A pesar de la existencia de posturas más consecuencialistas que la anterior en los sectores políticos más conservadores tanto de la política norteamericana como la europea, que opinan que aunque la constitución debe evolucionar hay un elemento "límite" determinante a tales cambios identificado por estas lecturas en el principio de seguridad jurídica, la literatura reciente, como Peter Häberle, reconoce que ambas tradiciones constitucionales, admiten mecanismos evolutivos, muchos de ellos de arraigo cultural, en la interpretación de la constitución, otros también, producto de los avances comunitarios, como la interpretación evolutiva de las constituciones europeas para promover el efecto útil ${ }^{11}$ del marco jurídico de la comunidad europea.

Para esta lectura no textual del poder de la interpretación, las evoluciones jurídicas muy radicales no son siempre deseables: algunas perturban el orden jurídico, lo que demanda precaución al momento de la interpretación, pues todas las decisiones judiciales dejan una marca en el sistema jurídico, que se debe justificar exclusivamente desde un verdadero objetivo constitucional que se busca alcanzar, encaminado a lograr un derecho más eficaz y más consiente de los cambios de las sociedades no solo a nivel interno sino también a nivel internacional. Estas concepciones acerca del nivel de permisión a la reforma a través de la interpretación, se reflejan en EE.UU. en modelos como el originalismo y el constitucionalismo viviente, que explicaremos más adelante.

Dentro de este debate entre persistencia o cambio en el que se ubica el poder de interpretación constitucional, ejercido tanto por jueces como por ciudadanos, se enmarcan en el contexto norteamericano, casos emblemáticos en los que justices históricos como Marshall ${ }^{12}$, Warren ${ }^{13}$ y el juez Scalia ${ }^{14}$, todos originalistas, marcaron precedentes determinantes en la jurisprudencia de la Corte Suprema de los Estados Unidos bajo la premisa del originalismo, que explicaremos en una sección adelante, y orientaron sus decisiones donde se fusionaron la Constitución, la historia y sin lugar a dudas la política y el

\footnotetext{
${ }^{10}$ BReYer (2005), p. 160.

11 Haberle (2002), p. 188.

12 Patrick (2010), p. 529.

${ }^{13}$ Cross (2012), p. 37.

${ }^{14}$ KanNar (1990), pp. 1297-1357.
} 
cambio social, en momentos donde el mero texto constitucional resultaba insuficiente.

En casos como Marbury vs. Madison, el caso Heller, el caso Brown Board vs. Education, casos emblemáticos del originalismo, hay evidencia que confirma que el sistema norteamericano obedece a un ejercicio colectivo de soberanía donde los jueces son intérpretes de un documento histórico pero a los cambios en las prácticas sociales y las enmiendas, con los que han hecho una constitución más democrática que se ha sometido a los procesos políticos del momento.

En Norteamérica, se tilda de justicia política a las decisiones que involucran no solo argumentos constitucionales sino de conveniencia social, y donde los jueces evalúan el alcance de una decisión político-jurídica, evaluación que sirve como un filtro más para determinar la conformidad a la constitución de dichas decisiones: la constitución no es solo lo escrito, es, también, lo socialmente conveniente ${ }^{15}$.

Por ejemplo, el caso Brown vs. Board of Education ${ }^{16}$, no solo es propiamente un ejercicio de debate constitucional en torno a la Enmienda Catorce, sino que sobre todo es un símbolo de la justicia racial que permitió futuros actos políticos, estatales y federales, de justicia política (campañas de desegregación de las escuelas y otros servicios). Casos como este demuestran la necesidad de reflexionar sobre la esencia de la interpretación judicial que, si bien es constitucional (jurídica), tiene un componente político que le permite a los jueces participar en la definición de las políticas públicas sin desconocer la esencia de la Constitución original, aquella redactada en $1787^{17}$.

\section{1. ¿Interpretación constitucional o interpretación política?}

De lo anterior es posible concluir que la principal inquietud actual sobre el problema de los métodos de interpretación en EE. UU. se centra en dos nociones que requieren ser definidas. La justicia política y la justicia

\footnotetext{
${ }^{15}$ Breyer (2005), pp. 151-178.

${ }^{16}$ En el caso Brown vs. Board of Education (U.S. Supreme Court. Brown vs. Board of Education of Topeka, 347 U.S. 483 (1954), se impugna la legalidad de leyes de segregación racial en las escuelas norteamericanas que practicaban la separación de estudiantes blancos y afroamericanos en instalaciones separadas, bajo el ejercicio de la doctrina "separados pero iguales", que aparentemente cumplía con el principio de igualdad formal ante la ley de la Enmienda Catorce. En la sentencia, la Corte Suprema se separa de su jurisprudencia anterior que permitía la segregación, indicando que, en materia de escuelas, la división es inherentemente violatoria del principio de igualdad así las instalaciones fueran iguales, pues promueve una sensación de inferioridad y afecta el proceso educativo.
}

17 Posner (2010), p. 330. 
constitucional. La pregunta que surge es si la Corte Suprema de Justicia, en el contexto norteamericano, pero, en general, cualquier alto tribunal, es un árbitro de la constitucionalidad o también un actor (y tal vez director) legítimo de los cambios sociales ${ }^{18}$.

La sentencia Brown vs. Board of Education es el resultado de un largo proceso que empezó con la abolición de la esclavitud en el siglo XIX, luego la proclamación de las leyes "separate but equal" adoptadas en 1896, para concluir con la abolición de la segregación en los establecimientos educativos del Sur de los Estados unidos, con la sentencia en 1954.

El principio de igualdad en la jurisprudencia de la Corte y en particular durante el periodo conocido como "La Corte Warren" (Periodo liderado por el Chief Justice Warren entre 1953-1969 en el que una mayoría de tendencia liberal lideró grandes cambios sociales en materia de derechos civiles, poderes federales, expansión del poder judicial y libertades civiles) se ha visto redefinido sociopolíticamente por diferentes momentos de cambio social impulsadas por el judicial. Para esta Corte, en el caso Brown, el retrógrado y segregador principio que regía la educación pública, "separados pero iguales", a pesar de su supuesta legalidad (el caso Plessy vs. Fergusson ${ }^{19}$ de 1896 consideraba la segregación como constitucional frente a la Enmienda Catorce Sección $1^{20}$ ), requiere ahora ser abolido por cuestiones de conveniencia social. Para la Corte Warren es insostenible que la segregación sea permitida solo porque la constitución no la prohíbe expresamente. La separación en la educación genera obligatoriamente desigualdad y la enmienda Catorce

\footnotetext{
${ }^{18}$ BEJA (2006), pp. 181-184.

${ }^{19}$ La sentencia Plessy vs. Fergusson (U.S. Supreme Court. Plessy vs. Ferguson, 163 U.S. 537 (1896), es el desafortunado precedente que permitió que las políticas de "separados pero iguales", abiertamente segregacionistas, fueran declaradas como constitucionales y así permanecieran de 1890 hasta 1954. En el caso, se impugna una ley de Louisiana que establecía que las empresas ferroviarias debían otorgar las mismas comodidades a blancos y afroamericanos, pero que podían hacerlo de manera separada (segregada). Adolph Plessy, ciudadano de Lousiana de origen mestizo y de antepasados en su mayoría blancos, se negó a abandonar el vagón exclusivo de ciudadanos blancos. La pregunta ante la Corte Suprema consistía en decidir si la medida de segregación constituía un caso de racismo o respetaba el mandato de protección igual ante la ley de la Enmienda Catorce de la constitución. En una lógica desafortunada, la Corte consideró que tal segregación no era en sí misma violatoria del derecho a la igualdad en tanto las instalaciones separadas otorgaran los mismos servicios, y que la enmienda catorce no podía forzar a las razas a mezclarse contra su voluntad. Esta decisión fue, como ya hemos anunciado, revocada en Brown vs. Board of Education.

${ }^{20}$ Enmienda Catorce Sección 1. Toda persona nacida o naturalizada en los Estados Unidos, y sujeta a su jurisdicción, es ciudadana de los Estados Unidos y del Estado en que resida. Ningún Estado podrá crear o implementar leyes que limiten los privilegios o inmunidades de los ciudadanos de los Estados Unidos; tampoco podrá ningún Estado privar a una persona de su vida, libertad o propiedad, sin un debido proceso legal; ni negar a persona alguna dentro de su jurisdicción la protección legal igualitaria.
} 
debe reinterpretarse para lograr una igualdad material y no solo formal. Estas problemáticas responden a la labor interpretativa y política de la Corte, pero restringida en su campo de acción a los métodos de interpretación como el originalismo o el constitucionalismo.

Casos como Brown ponen de presente que la tradición constitucional norteamericana busca el objetivo fundamental de perfeccionar la democracia mediante la protección del orden jurídico en sede judicial y el balance de poderes entre mayorías, que dominan el legislativo, y minorías protegidas por los jueces ${ }^{21}$.

Es menester mencionar como, aquella postura no está exenta de objeciones, tanto en la doctrina como en algunos jueces de la Corte Suprema: autores tanto tradicionales como Henkin ${ }^{22}$ o más recientes como Barkow ${ }^{23}$, bien sea basados en otros principios de la democracia o límites internos de la actividad judicial, ponen de presente que parte del asunto puede estar en la localización de problemas de carácter político en los foros de los jueces, mas no en lo que consideran su lugar más habitual, como el congreso, así sea el del modelo federal. Para ello, defienden la doctrina de la political question, que propende por que los jueces mismos se cuestionen si tienen competencia sobre un asunto, en el entendido que la naturaleza del mismo puede ser solo de fondo político y debe ser, por deferencia, remitido al legislador.

De esta forma, las teorías sobre la práctica de la interpretación constitucional norteamericana cuestionan el modelo constitucional meramente sujeto a lo escrito y a la subsunción y aceptan que, en la práctica constitucional, los jueces tienen a su cargo la definición de grandes libertades, políticas y derechos que no siempre son garantizados por el proceso político legislativo, pero que encuentran una protección en la esfera judicial. Así, los jueces son partícipes de un modelo de justicia constitucional que también busca la justicia política, asociado la labor de los jueces con las necesidades de la sociedad, lo que la doctrina ha llamado la interpretación con ideal asociativo, al juntar los intereses de los jueces y la sociedad $^{24}$. Estas mismas características son identificadas por autores como Eduardo Aldunate, en el incremento de la justicia constitucional, la relación juez-sociedad, el superar los métodos tradicionales de resolver contradicciones

\footnotetext{
${ }^{21}$ SANDALOW (1977), pp. 1162-1195.

22 Henkin (1976), p. 598.

${ }^{23}$ BARKOW (2002), pp. 237-238.

${ }^{24}$ SAGer (2007), p. 87.
} 
constitucionales-legales y la constante resolución judicial de colisiones entre derechos y normas constitucionales, como rasgos del neoconstitucionalismo ${ }^{25}$.

\section{La Constitución histórica y los métodos de interpretación constitucional norteamericanos como desarrollo jurisprudencial y como interacción entre procesos jurídicos y tendencias políticas}

\subsection{La Constitución y el Juez Marshall: La interpretación constitucional como construcción constitucional}

Desde que el juez Marshall escribiera en su histórica opinion para el caso Marbury vs. Madison ${ }^{26}$ la inmortal frase que funda el control constitucional concentrado como lo conocemos hoy; "It is emphatically the province and duty of the judicial department to say what the law is... If two laws conflict with each other, the courts must decide on the operation of each (...) This is of the very essence of judicial duty."(traducción en pie de página) ${ }^{27-28}$, no solo se ha expandido el control constitucional, el judicial review, al grueso de las repúblicas americanas, sino que también, desde ese mismo instante, se instauró en la doctrina constitucional el debate acerca de cómo interpretar de forma adecuada la carta política, para guardar la integridad de la constitución pero también para atender las reformas sociales que discutíamos anteriormente.

El caso Marbury vs. Madison es en sí mismo una gran paradoja frente al control constitucional y la interpretación constitucional. En la decisión, se establece la supremacía de la constitución sobre todo el orden jurídico y el rol del juez como encargado del control constitucional. En el caso concreto, se establecen estas dos ideas con una tarea específica: oponerse específicamente a la aplicación y permanencia en el naciente orden jurídico federal norteamericano del momento, de una ley que adicionaba funciones no previstas en la constitución, al poder judicial ${ }^{29}$.

En Marbury, de alguna manera se funda un nuevo poder, uno general y sistemático; el control constitucional, para negar otro poder incidental que nacía de la ley que fue objeto de control: una jurisdicción especial dada a la

\footnotetext{
${ }^{25}$ Aldunate (2010) p. 95.

${ }^{26}$ U.S. Supreme Court. Marbury vs. Madison, 5 U.S. 137 (1803).

${ }^{27}$ Traducción Libre: "Es enfáticamente la providencia y el deber del poder judicial decir qué es la ley, si dos leyes entran en conflicto entre sí, las cortes deben decidir sobre la relación entre ellas, esta es la mera esencia del deber judicial".

${ }^{28}$ U.S. Supreme Court. Marbury vs. Madison, 5 U.S. 137, (1803) p. 178.

${ }^{29}$ CHEMERINSKY (2006).
} 
Corte Suprema por una ley coyuntural, para decidir sobre el nombramiento de jueces de menor jerarquía.

La ley en cuestión, como bien se conoce, no era más que una norma que otorgaba competencias nuevas a la Corte Suprema (jurisdicción originaria para decidir sobre asuntos relativos al nombramiento de Jueces de Paz ${ }^{30}$ ): poderes nuevos y distintos a los que ya prescribía la Constitución: Marshall entendió que una Ley Federal no podía decir nada distinto a la Constitución, incluso, nada-adicional-: El gran oxímoron detrás de su decisión es que precisamente, el judicial review, el poder de control constitucional, tal y como la competencia que le daba la ley que decidió declarar inconstitucional, sufre el mismo defecto: no estar escrito en la Constitución ${ }^{31}$.

A pesar de la paradoja, el legado del juez Marshall en Marbury es innegable y darles a los jueces el poder de decidir "qué es y qué no es el derecho" es la base del constitucionalismo material hoy, pero, desde el mismo instante de su decisión, la pregunta sobre cómo interpretar la constitución ha sido permanente: ¿la constitución es solo lo en ella escrito?, ¿es el significado original o moderno de las palabras allí consignadas?, ¿es la intención de sus redactores?, ¿es el consenso político de la época de su promulgación?, ¿es lo que la sociedad espera de ella en distintas épocas?

Todas estas preguntas se relacionan con dos macrointerrogantes que para la teoría constitucional son estructurales: El primero: preguntarse si la Carta cambia con el tiempo en su alcance y contenido o si, por el contrario, es estática, pétrea. El segundo interrogante busca entender los límites que los jueces de constitucionalidad deben observar a la hora de interpretar el contenido de la constitución: ¿Existen límites a la labor interpretativa del juez? ¿Esos límites están en la misma carta o son autoimpuestos por el juez a su propio comportamiento?

Aquellos interrogantes ya se debatían en la época de Marshall, antes de la promulgación de la Constitución de Estados Unidos y, por supuesto, antes y después de su famosa sentencia ${ }^{32}$. Anecdóticamente, hay quienes castigan de falaz o activista $^{33}$ el principio enunciado en el caso Marbury vs. Madison por

\footnotetext{
${ }^{30}$ Judiciary Act of $1789, \S 13:$ The Supreme Court shall also have appellate jurisdiction from the circuit courts and courts of the several states, in the cases herein after provided for; and shall have power to issue writs of prohibition to the district courts [...] and writs of mandamus [...] to any courts appointed, or persons holding office, under the authority of the United States.

${ }^{31}$ Las secciones II y III del Art. 3 de la Constitución norteamericana no incluyen, por lo menos, de forma taxativa, la función de declarar como inconstitucionales las normas de menor jerarquía que sean opuestas a la misma.

${ }^{32}$ O'NelLL (2002), pp. 792-802.

33 Goldstone (2010).
} 
hacer referencia a un poder de control constitucional no escrito ${ }^{34}$ y otros, que en un ejercicio histórico, encuentran evidencia de cómo Madison y Jefferson, en los trabajos preparatorios del documento constitucional, ya habían planteado la posibilidad de un poder de revisión judicial de la constitución antes de que esta fuera promulgada, justificando así la decisión de Marshall desde la intención original de los redactores ${ }^{35}$.

El modelo constitucional del federalismo norteamericano siempre ha girado alrededor de la noción de poderes enumerados, residuales, no expandibles ${ }^{36}$ y la interrelación entre los pesos y contrapesos clásicos del liberalismo político ${ }^{37}$ con las dinámicas entre lo local y lo nacional en el modelo federal, por ello la interpretación constitucional en esta forma de common law es vista no solo como un requisito de motivación, sino como un límite al juez, pero también como una potestad federal, incluso, suele llamarse construcción constitucional ${ }^{38}$, al entender que se ubica en un plano incierto del ejercicio jurisdiccional: darle vida y sentido a una constitución histórica frente a los problemas jurídicos recientes y futuros, muchos de ellos tal vez nunca previstos por los padres fundadores ${ }^{39}$.

El siguiente apartado pretende explorar los métodos de interpretación constitucional que la jurisprudencia ha forjado a lo largo de la experiencia constitucional norteamericana y que, aunque han sido objeto de estudio de manera tangencial para la doctrina jurídica norteamericana, han recibido poca atención por parte de los estudios constitucionales latinoamericanos en castellano y, mucho menos, han sido juiciosamente comparados con los propios métodos empleados por los jueces latinoamericanos, tal vez por la distancia entre las constituciones latinoamericanas recientes, más normativas, reguladoras, modernas y legalistas, pero tan susceptibles a la constante reforma por la constante urgencia de reformas técnicas de nuestros Estados ${ }^{40}$, frente a la constitución norteamericana, decididamente inmutable, histórica y modificada más por la interpretación de los jueces a lo largo del tiempo, que por el puñado de enmiendas escritas que conocemos.

\footnotetext{
34 Marion (2005), p. 1041.

${ }^{35}$ Lloyd (2013), pp. 20-50.

${ }^{36}$ Natelson (2002), p. 469.

37 HuYLeR (1995).

${ }^{38}$ WhitTington (2009).

${ }^{39}$ EidelberG (1986).

${ }^{40}$ Esquirol (2008), pp. 75-124.
} 


\subsection{Los métodos de interpretación constitucional como resultado de la jurisprudencia norteamericana y de la necesidad de aplicar y modificar una constitución histórica}

La historicidad y permanencia de las instituciones jurídicas constitucionales norteamericanas y su existencia dentro de un sistema de common law que les precede, definen la forma en que se han ido construyendo los métodos de interpretación en el sistema norteamericano.

A diferencia de los sistemas jurídicos latinoamericanos y sus reformas más recientes, donde tienen vigencia constituciones más modernas, recientemente promulgadas, reguladoras de todos los fenómenos públicos y privados dentro del sistema jurídico ${ }^{41}$, extensas, altamente técnicas ${ }^{42}$ y usualmente acompañadas de códigos civiles y otras leyes escritas, tanto sustantivas como procedimentales que establecen, recopilan y ordenan las formas de aplicar e interpretar la ley, usualmente de naturaleza gramatical (Ej.: Código Civil Colombiano, Capítulo IV. interpretación de la $\left.l e y^{43}\right)$, y junto a ellas, grandes modelos doctrinales que estudian y reformulan la interpretación de la ley escrita, el constitucionalismo norteamericano siempre ha encontrado el origen de sus métodos de interpretación en los jueces mismos y en sentencias que se van volviendo referentes para cada uno de los métodos de interpretación, casi de forma casual e incidental ${ }^{44}$. Una sentencia que aplique de forma clara un método de interpretación, de repente, puede tornarse en el máximo referente de enseñanza del mismo.

En ese contexto, los métodos de interpretación del constitucionalismo norteamericano ante todo son resultado de los diferentes tipos de argumento que a lo largo de la vigencia de más de 227 años de la constitución norteamericana se han construido en las opiniones de los jueces de la Corte Suprema y otras instancias, en su constante intento por darles vida y significado a las expresiones escritas en ese documento fundacional que tal vez, por su sencillez, no ha tenido problemas en ser adaptado a las más variadas demandas de la realidad, en un

\footnotetext{
${ }^{41}$ PASTOR (2011), pp. 1-24.

${ }^{42}$ Gargarella (1997), pp. 971-990.

${ }^{43}$ Código Civil Colombiano.

Capítulo iv.

Interpretación de la ley

Artículo 25. Interpretación por el legislador. Artículo 26. Interpretación doctrinal.

Artículo 27. Interpretación gramatical.

Artículo 28. Significado de las palabras. Artículo 29. Palabras técnicas artículo 30. Interpretación por contexto.

Artículo 31. Interpretación sobre la extensión de una ley. Artículo 32. Criterios subsidiarios de interpretación.

${ }^{44}$ Strauss (1996), pp. 877-935.
} 
ejercicio que siempre ha girado alrededor de la incógnita sobre la verdadera intención de los redactores de la misma ${ }^{45}$ y la búsqueda, algunas veces posible, otras veces complicada, casi mística, de lo que estos hombres históricos podrían opinar de los fenómenos de hoy.

\subsection{Constitución Histórica, Escrita y Original versus Constitución Viviente y Cambiante}

Las dos posturas más reconocidas sobre cómo entender la constitución, posturas de donde brotan los métodos de interpretación en el sistema jurídico norteamericano, son el originalism (originalismo) y el living constitucionalism (constitución viva), y representan modelos de pensamiento que reflejan las dos opciones interpretativas que suelen debatirse al momento de preguntarse cómo entender la constitución ${ }^{46}$.

La primera de las opciones, el originalismo, promueve la estabilidad, inmutabilidad y vocación de permanencia de la Constitución, tanto en su contenido, como en el significado del mismo: La constitución al recoger los principios esenciales construidos para la nación por los Padres Fundadores, no debe cambiar salvo por enmiendas de tipo formal (que implican un procedimiento interinstitucional y complejo ${ }^{47}$ ) y quienes la interpretan deben respetar su contenido original y significado esencial, histórico ${ }^{48}$, pues son las ideas y formas de ver el mundo en 1790, creadoras de la nación, las que tienen valor jurídico en el documento y en las que se consigna la legitimidad democrática.

Esta postura pétrea frente al contenido de la constitución promueve un conjunto de métodos conocido como históricos u originalistas, que se remiten a los significados originales del texto, a su contexto histórico, al significado de las palabras de la época e incluso a los trabajos preparatorios de los redactores de la misma para analizar todo caso de orden constitucional, siempre bajo dos preguntas: ¿Cuál es el significado original de lo dicho por la Constitución en X materia? y ¿Cuál sería la postura de los Padres Fundadores, redactores de la constitución, frente al problema planteado? ${ }^{49}$.

La postura pétrea frente al significado de la Constitución no escapa a las críticas, como las de aquellos que reproducen el famoso argumento que indica que desde el punto de vista democrático el originalismo más recio implica limitar

\footnotetext{
45 Sandalow (1981), pp. 1033-1072.

46 AMAR (2012), p. 195.

${ }^{47} \mathrm{RASCH}(2006)$, p. 319.

${ }^{48}$ Goldsworthy (1997).

${ }^{49}$ Strauss (1996), pp. 877-935.
} 
el destino de las generaciones presentes a lo decidido por individuos de siglos atrás con los cuales pueden no tener nada en común, afectando la representatividad dentro de la decisión judicial, un valor moderno de la democracia ${ }^{50}$, o aquellos que temen que el originalismo sea un método para imponer posiciones jurisprudenciales de corte conservador ${ }^{51}$, tradicionalista $^{52}$ e incluso nacionalista.

La otra posición (living constitucionalism) promueve lo que se ha llamado una constitución viviente, entendida como aquella cuyo significado, alcance e interpretación debe cambiar con el tiempo a medida que las circunstancias lo demandan, por ejemplo, los cambios en las relaciones sociales, en la cultura, en la conformación demográfica del país, en la economía, etc. Todo ello, sin implicar enmiendas de carácter formal, sino a través de interpretaciones jurisprudenciales que, sin desconocer los más esenciales principios históricos previstos por los padres fundadores, permitan moldear la constitución a la cambiante realidad, implicando con ello un flujo de decisiones judiciales modernizantes que ofrezcan respuestas innovadoras, más allá de lo que el texto mismo de la constitución dictamine de forma taxativa, en tanto el significado de sus palabras debe cambiar con el paso de la historia y es la tarea del juez interpretar estos cambios y los nuevos significados de la constitución.

Por supuesto, los cambios que fundamentan esta postura no son las típicas, simples y sencillas circunstancias del día a día de la sociedad norteamericana: son los inconmensurables cambios en la tecnología, en la conformación de la sociedad, en la economía, en la demografía del país, en la configuración de la sociedad internacional, en la globalización, las grandes crisis sociales, las que motivan una constitución adaptativa, presta a cambiar de forma, al momento que es leída por los jueces, para responder a las nuevas demandas sociales y culturales que escapan a su texto ${ }^{53}$.

El constitucionalismo viviente no escapa a los críticos, que por ejemplo, consideran que tal posición no originalista implica la personalización de la Carta, pues su significado termina siendo no lo escrito en ella, lo originalmente pactado, sino lo que considere un juez determinado, sometiéndola a mayores indeterminaciones, a los cambios y sentires de los sujetos, a la captura por parte de ideologías. A su vez, muchos consideran que interpretaciones más modernas de la constitución son un instrumento necesario de cambio, de inclusión y de participación democrática, incluso de activismo judicial, que han permitido los

\footnotetext{
50 SimON (1985), pp. 1482-1539.

${ }^{51}$ FALLON (2011), p. 5.

52 Burgess (2013).

${ }^{53}$ Strauss (2010).
} 
grandes cambios jurisprudenciales en el sistema ${ }^{54}$, como los giros históricos en materia de derechos civiles ${ }^{55}$, la expansión del significado de las enmiendas y el desarrollo de nuevas teorías de derechos civiles para incluir elementos no escritos como la libertad en la orientación sexual ${ }^{56}$, a partir de partes escritas de la constitución que son gramaticalmente escuetas y que no hacen referencia a los derechos en cuestión, como la Quinta Enmienda en materia de debido proceso o la Decimocuarta Enmienda, de las cuales, desde el constitucionalismo viviente, se han derivado derechos no escritos ${ }^{57} \operatorname{como~la~privacidad~}^{58}$ y la libertad sexual ${ }^{59}$.

\subsection{La Tercera Vía: Precedente y el Common Law Constitucional}

Frente a tal disyuntiva entre dos modelos, no todas las posiciones son extremas. Actualmente, se hacen fuertes, especialmente en materia de derechos fundamentales, las posturas de autores que favorecen un nuevo entendimiento del sistema constitucional norteamericano no como meramente histórico o como absolutamente sometido al activismo judicial, sino como un "constitucionalismo de precedente" (common law constitution).

Esta idea reconcilia los dos modelos anteriormente explicados, construyendo un sistema dual donde "la constitución" norteamericana ya no es solo el antiguo documento escrito, sino un sistema constituido por las sentencias y las interpretaciones, test y métodos que en ellas se proponen, a la par de la constitución escrita $^{60}$, todas con rango de criterio de constitucionalidad, en tanto los apartes más esenciales de la Carta escrita constituyen los límites materiales a las interpretaciones más arriesgadas (originalismo), pero el conjunto de sentencias que han ido modificando su significado son el criterio de construcción de nuevas lecturas (constitucionalismo viviente) y a la vez construyen precedentes que no pueden ser fácilmente ignorados o revertidos.

Esta nueva postura ha sido defendida por sus promotores, mediante la ejemplificación misma de la estructura moderna de casi cualquier decisión de la Corte Suprema hoy, donde la Constitución tiene un rol ceremonial, casi de referencia, como punto inicial de enunciación del problema jurídico, pero toda la opinion gira

\footnotetext{
${ }^{54}$ DuBois (1987), pp. 836-862.

${ }^{55}$ U.S. Supreme Court. Heart of Atlanta Motel Inc. vs. United States, 379 U.S. 241 (1964).

${ }^{56}$ SUNSTEIN (1988), p. 1161.

${ }^{57}$ CRUz (2000).

${ }^{58}$ RiCHARDS (1978), p. 957.

${ }^{59}$ MiLleR (1979).

${ }^{60}$ Strauss (2010).
} 
alrededor de precedentes interpretando la constitución y el juez, más que aplicar de forma textual la constitución, busca el precedente constitucional correcto, ${ }^{61}$ más allá de una mera subsunción o aplicación constitucional de artículos al caso concreto, que para los constitucionalistas norteamericanos es un proceso que ya es solo posible para la aplicación de las leyes (statutes) pero no de la carta política:

El contraste entre el derecho constitucional y la interpretación de los estatutos (leyes) es particularmente revelador. Cuando un caso se refiere a la interpretación de la ley, los memoriales, los argumentos orales, y las sentencias por lo general se centran en las palabras exactas de la ley. Pero cuando un caso se refiere a la Constitución, el texto rutinariamente no recibe ninguna atención. A diario, el derecho constitucional de Estados Unidos se desarrolla alrededor de precedentes, y cuando los precedentes no son suficientes, se trata de nociones de sentido común, de la equidad y la buena política.

¿Qué está pasando aquí? ¿No tenemos una Constitución? Lo hacemos, pero si crees que la Constitución es el documento que está bajo el vidrio en el Archivo Nacional, nunca vas a entender el derecho constitucional americano. Nuestra nación tiene más de dos siglos de experiencia que se enfrentan a las cuestiones constitucionales, cuestiones fundamentales que surgen en un complejo, diverso, y cambiante contexto social. Las lecciones que hemos aprendido en lidiar con esos problemas sólo a veces se abren camino en el texto de la Constitución por vía de enmiendas, e incluso entonces las enmiendas a menudo se producen sólo después de que la ley ya ha cambiado.

Pero esas lecciones se incorporan de forma rutinaria en los casos que el Tribunal Supremo decide, y también, sobre todo, en las tradiciones y entendimientos que se han desarrollado fuera de los tribunales. Esos precedentes, tradiciones y entendimientos forman una parte indispensable de la constitución, son ella misma ${ }^{62}$.

\section{5. ¿Eran los Padres Fundadores Originalistas? ¿Aceptarían el Constitucionalismo Viviente?}

Aun así, los análisis conciliadores no son exóticos o nuevos, es más, existen documentos históricos (por tanto originalistas) que podrían señalar el camino,

\footnotetext{
${ }^{61}$ Strauss (2010), p. 973.

${ }^{62}$ Strauss (2010), p. 974.
} 
los que presentamos brevemente en este apartado para suscitar el debate más allá de desarrollarlo plenamente en la presente contribución, con el fin de que sea tenido en cuenta este punto durante la lectura de la misma: ¿Qué ocurriría si los Padres Fundadores fueran, por sí mismos, no originalistas? ¿El hecho de probarlo sería darle la razón al originalismo? (al usar la historia como fuente de la respuesta, por tanto, aplicándolo) ¿ o condenarlo? (¿al encontrar en la historia, un argumento típico del constitucionalismo viviente, para evitar el exceso de originalismo?). Ese es el curioso caso, por ejemplo, de algunas afirmaciones históricas de Thomas Jefferson:

Carta de Thomas Jefferson a Samuel Kercheval, julio 12, 1816:

"Ciertamente no soy un defensor de cambios frecuentes y no probados, en leyes y constituciones. Creo que imperfecciones moderadas se soportan mejor porque, una vez conocidas, nos acomodamos a ellas y encontramos los medios prácticos para corregir sus efectos nocivos. Pero sé también que las leyes y las instituciones deben ir de la mano con el progreso de la mente humana. Conforme más se desarrolla más se ilumina y conforme se hacen nuevos descubrimientos, se revelan nuevas verdades, y cambian las opiniones y las modales con el cambio de circunstancias, las instituciones deben avanzar también y mantener el ritmo de los tiempos" ${ }^{\prime 63}$.

Tales afirmaciones de Jefferson para algunos indican que los mismos padres fundadores aceptaban una constitución maleable y sujeta a interpretaciones, conscientes de los cambios que vienen con el tiempo, pero también atenta a la inmanencia de sus principios. Podría considerarse esto como la verificación originalista -en tanto se acude a fuentes históricas específicas- de la validez del no originalismo, pero, a su vez, un ejemplo de la importancia del método histórico, siendo aquí aplicado para justificar determinada interpretación de la constitución. Toda una muestra de esta constante paradoja.

\subsection{Clasificaciones de los métodos de interpretación en el sistema constitucional norteamericano}

Varios métodos y submétodos de interpretación pueden ser catalogados y agrupados en esta dualidad de originalismo versus no originalismo (living constitutionalism), afiliando a cada uno de ellos distintos procedimientos (más jurisprudenciales que técnicos) de interpretación que optan por la historia estática o la constitución viva y modificable, pero desde ópticas distintas, como la revisión minuciosa del texto

\footnotetext{
${ }^{63} \mathrm{http}: / /$ memory.loc.gov/cgi-bin/ampage?collld=mtj1 \&fileName=mtj1 page049.db\&recNum=254 The Thomas Jefferson Papers Series 1. General Correspondence. 1651-1827.

Thomas Jefferson to Samuel Kercheval, July 12, 1816.
} 
en completo desde el punto de vista gramatical, el significado histórico o moderno de las palabras, el rastreo de las intenciones de los constituyentes, leer de forma histórica algunos apartes de una cláusula y otros de forma viviente o "modificada", contemplar el impacto social de una posible decisión o recurrir a las ciencias duras para resolver dilemas científicos dentro de una decisión.

\begin{tabular}{|l|l|}
\hline \multicolumn{2}{|c|}{$\begin{array}{c}\text { Modelos y Métodos de Interpretación Constitucional } \\
\text { en el Sistema Jurídico Norteamericano }\end{array}$} \\
\hline \multicolumn{1}{|c|}{ ORIGINALISMO } & \multicolumn{1}{c|}{$\begin{array}{c}\text { NO ORIGINALISMO } \\
\text { (LIVING CONSTITUTION) }\end{array}$} \\
\hline Textualismo & $\begin{array}{l}\text { Constitucionalismo Viviente - Test de } \\
\text { Escrutinio }\end{array}$ \\
\hline Significado Original (Original Meaning) & Impacto social (Aggregate effect) \\
\hline Intención Original (Original Intent) & Deferencia a los expertos \\
\hline Originalismo Modificado & Originalismo Modificado \\
\hline
\end{tabular}

Tabla 1: Elaborada por los autores.

\section{Originalismo.}

\subsection{Fundamento jurídico-político del Originalismo}

Bajo este esquema, forman parte del originalismo todos los métodos que sin importar su objeto de estudio principal (texto histórico como un todo, significados gramaticales históricos, intención de los redactores, etc. ${ }^{64}$ ) consideran que el trabajo de los padres fundadores, de los redactores de la constitución, the framers, es el punto de partida de toda interpretación en tanto los consideran la autoridad política de la que emana el pacto constitucional: En ello, el originalismo no se aleja de muchas otras prácticas constitucionales, tanto continentales como anglosajonas, que derivan el poder emanado de la constitución, del pacto original, de un contrato social y un soberano y constituyente histórico ${ }^{65}$. Toda legitimidad, para el originalismo, emana de este conjunto concreto de ideales que representan los padres fundadores y de su máxima obra, la constitución, que contiene en sí misma su voluntad política originaria y constituyente ${ }^{66}$.

Esta idea principalista que manifiesta que la constitución debe ser obedecida según su tenor original pues es aquel el que representa el pacto original y fundacional de la nación, ha sido llamada en la doctrina norteamericana como

${ }^{64}$ MCGINNIS (2007).

${ }^{65}$ O'NeILL (2005).

${ }^{66}$ Strauss (1996), pp. 888-902. 
Convencionalismo: es convencionalista todo aquel que reconoce obligatoriedad y fuerza vinculante en la constitución (específicamente en el tenor literal de su texto) al entenderla como el producto directo de los trabajos de los padres fundadores, los constituyentes, durante la Convención de Filadelfia, de mayo a septiembre de 1787.

\subsection{Dimensión Política del Originalismo}

El originalismo como práctica constitucional cuenta con diferentes rasgos de justificación política, entre los que tenemos, en primer lugar, la agencia pura. Una actitud activa frente al contenido de la constitución como legado del pasado en donde la interpretación de la constitución no es "un juicio normativo contemporáneo" ${ }^{\prime \prime 7}$, la interpretación de la constitución es un acto de la recuperación del contenido de la constitución en el pasado que, para sus defensores, debe ser el ideal de la función judicial.

Se trata de mirar la constitución y revelar su contenido original y los "principios básicos" que definen cómo los jueces deben interpretar la constitución escrita cuando la constitución deja vacíos o situaciones sin solución: En el caso de los vacíos se debe permitir que el "proceso político democrático" encuentre el significado, pero no mediante consultas populares modernas, sino con una interpretación histórica que trata de descifrar el sentido de los padres fundadores ${ }^{68}$.

En segundo lugar, tenemos la agencia moderada, una vertiente del originalismo que también se denomina "teorías reticentes acerca de la admisibilidad de juicios normativos de tribunales (reluctant judgment theories)", que reconocen que la constitución histórica debe ser reinterpretada con el paso del tiempo y por ende hay un juicio normativo por parte de los jueces, pero que se debe conciliar siempre con la constitución histórica escrita, que es la única autoritativa.

Esta aproximación implica buscar con método originalista los límites a la labor del constitucionalismo viviente parcialmente aceptado como necesario. Los jueces siguen instrucciones y emiten juicios en algunos casos apartados del significado original, pero solo por "por necesidad y con reticencia" 69 .

Desde un punto de vista crítico a este modelo, Lawrence Sager afirma que en definitiva el juez de la Corte Suprema que defiende la tesis originalista en pos de defender un consenso político de los constituyentes que ya desaparecieron trata de rescatar "un juicio estancado, de una generación política que nunca pretendió convertir ese juicio en derecho"70, situación inaceptable desde la perspectiva de la democracia. Agrega: "Si el texto y el contexto de la Constitución no nos

\footnotetext{
${ }^{67}$ SAGer (2007), pp. 41-54.

68 SAGer (2007), p. 44.

${ }^{69}$ ACKerman (2011).

70 SAGER (2007), pp. 65-77.
} 
indican un resultado único, la tesis originalista fracasa por la más mundana de las razones: no puede ofrecer respuesta a las cuestiones que preocupan al derecho constitucional moderno"71.

De esta forma, el "originalismo modesto" es aquel que complementa el texto de la constitución de dos maneras, la primera, cumpliendo con ciertas expectativas de los constituyentes originarios, y la segunda, dándoles alcance a los "principios morales y políticos que los constituyentes querían expresar"72. Este "originalismo modesto" acepta que los jueces establezcan sus propios juicios modernos, "utilizando recursos normativos propios", pero limitados por los principios establecidos por los constituyentes, que se traducen en cláusulas garantes de la libertad, que son solo puntos de partida para realizar cualquier juicio, de acuerdo con Michael McConnell y Sager ${ }^{73}$, es, en cierta forma, una interpretación no originalista, dado que las cláusulas constitucionales pueden ser un mero referente histórico y no "una expresión directa de principio sustantivos"74.

Esta versión del originalismo desde su fundamento políticoes parte de las teorías reticentes porque consideran que ser fiel a la constitución literal es imposible en la medida en la que el juez siempre ejerce un juicio normativo al traducir el tenor del texto original, lo que jamás estará exento de juicios por parte de los jueces ${ }^{75}$.

En este modelo de agencia, la actividad de interpretación de las leyes hace que los jueces interactúen con el legislador en una actividad de colaboración.

\section{Constitucionalismo viviente y no originalismo}

\subsection{Fundamento jurídico-político del No Originalismo}

Si bien el convencionalismo es un buen sustento para los argumentos de corte originalista, las doctrinas no-originalistas también encuentran justificaciones más allá de la previamente explicada fundamentación desde constitucionalismo viviente.

Los no originalistas encuentran en el comportamiento de los jueces suficientes razones para apoyar un método constitucional no-originalista: Al resaltar como los jueces han ido modificando el contenido de distintas cláusulas,

${ }^{71}$ SAGER (2007), p.76.

72 SAGer (2007), p. 81.

${ }^{73}$ Sager (2007), p. 81.

${ }^{74}$ SAGER (2007), p. 81.

${ }^{75}$ LESSIG (1992), p. 1165. 
como la cláusula de comercio ${ }^{76}$, o interpretado de forma amplia y no explícita el contenido de las enmiendas, han desarrollado las teorías de la innovación (innovation) y de la posición privilegiada (preferred position).

La innovación consiste en la necesidad de modificar el contenido de las cláusulas a medida que pasa el tiempo, tarea que deben hacer los jueces contemporáneos al problema, para no someter a los sujetos actuales a las ideas de individuos pasados.

La doctrina de la posición privilegiada busca defender que la jurisprudencia constitucional demuestra que, más allá de un texto plano que le da el mismo valor textual a todas sus cláusulas, la constitución norteamericana tiene-disposiciones más importantes que otras- y que son precisamente esas cláusula más trascendentes, las que merecen ser interpretadas de una forma viva. Por ejemplo, es necesario encontrar derechos implícitos, no textuales, en enmiendas como la Decimocuarta, donde jueces no originalistas han encontrado, por ejemplo (y sentado jurisprudencia al respecto) el derecho a la privacidad, aunque no se encuentre escrito ${ }^{77}$.

\subsection{La constitución viviente como modelo de colaboración entre poderes}

Para algunos autores, el constitucionalismo viviente es una teoría democraticista o teoría de la colaboración, que le da al juez un carácter fundamental en la definición de la constitución pues admite una colaboración conjunta entre el constituyente primario que se expresa de manera general y el juez constitucional que complementa los postulados iniciales de manera "reflexiva"78 garantizando la justicia política, alejado de toda imposición originalista ${ }^{79}$. Otros Ilaman a esta práctica la tendencia modernista o activista, dedicada a la reinterpretación de la constitución en virtud de la evolución de la sociedad.

Este modelo considera a los jueces constitucionales como colaboradores activos quienes a través de los "juicios normativos" del contenido de la Constitución contribuyen con la justicia social ante injusticias y disparidades actuales, por lo tanto, bajo esta perspectiva los jueces no siguen instrucciones de los Framers o simplemente "traducen" un pasado plasmado en la Constitución.

Para este modelo, vincular a los jueces en la definición constante y moderna de la Constitución es una garantía de independencia de los jueces y de su libertad. Los jueces constitucionales tienen una sola limitación, que se denomina

\footnotetext{
76 Graglia, (1995), p. 719.

77 U.S. Supreme Court. Meyer vs. Nebraska, 262 U.S. 390 (1923).

78 SAGer (2007), p. 87.

${ }^{79}$ SAGER (2007), pp.65- 77.
} 
"la regla del mejor juicio": estar encaminado hacia encontrar siempre una mejor interpretación de cada uno de los principios escritos: es un juicio pragmático, donde se concibe una colaboración entre el poder constituyente y el intérprete judicial que "define" los principios generales de la constitución y su alcance moderno. Esta práctica se perfila a su vez como un constitucionalismo al servicio de la justicia social ${ }^{80}$.

También hay una vertiente moderada del constitucionalismo viviente, que se denomina "teoría democraticista" que reconoce y valora el juicio normativo e independiente de los jueces, pero solo siempre y cuando se haga para mejorar y enmendar falencias evidentes en el proceso democrático. Esta teoría encuentra sus críticas en quienes argumentan que toda actividad judicial se justifica únicamente para mejorar la democracia. Este juez tendrá una doble posición, si se trata de defender la democracia debe actuar como un defensor de los modelos basados en la justicia, y en lo demás actuará como un originalista.

"Por consiguiente, en algún sentido todos los modelos plausibles del papel de los jueces constitucionales, tratan a los jueces como seguidores de instrucciones (...) desde esta perspectiva, la diferencia entre teóricos originalistas, "reticentes", y democraticistas reside en su diversa concepción acerca de la naturaleza de las instrucciones que emanan de la Constitución escrita, una diferencia que es particularmente profunda en relación con las cláusulas constitucionales que garantizan la libertad"81.

Adicionalmente, se pueden establecer algunos paralelismos entre la idea norteamericana del no originalismo a través de la living constitution, con elementos de reflexiones europeas sobre el poder constituyente, la constitución y la interpretación, lo que ayuda a entender que no son mundos enfrentados. Por ejemplo, en las ideas esenciales de Schmitt, se evidencia como la preexistencia, supervivencia e identificación del poder constituyente con el pueblo (homogéneo en su poder de decisión pero diverso en sus aportes a la democracia) permiten entender que el primer acto constituyente, la promulgación de una constitución histórica, no implica que el poder constituyente fuese agotado, por el contrario, ese puede aparecer en cualquier momento, reinterpretarla, renovarla, modificarla ${ }^{82}$, premisa y nociones "continentales", reconocidas también por otros autores mencionados en diferentes partes de este texto como Haberle, Hesse y Aldunate, que en su contenido también son cercanas al no originalismo.

\footnotetext{
${ }^{80}$ SAGer (2007), p. 77.

${ }^{81}$ SAGer (2007), pp. 52-53.

${ }^{82}$ SСнмiтt (2007), pp. 200-218.
} 
Aquella relación entre la necesidad social de actualizar los contenidos constitucionales, la excepcionalidad de la reforma formal, los cambios sociales como propósito en la reinterpretación de la constitución por vía judicial y en general, las propuestas y tensiones entre originalismo y no originalismo son estudiadas y referidas también como naturales a la tradición continental (lo que demuestra el punto de encuentro en ello con el mundo anglosajón) por autores como Zagrebelsky en sus reflexiones sobre la actividad judicial en el ámbito constitucional:

"La Constitución no se cambia como una ley cualquiera, ni prescribe en una fecha determinada. Entre la generación constituyente y las sucesivas se instituye una relación como la que existe entre padres (los "padres fundadores") y los hijos sucesores. A cada generación de herederos le corresponde "mejorar y perpetuar", no echar al viento el legado, el legado recibido. La ley de la buena vida de las Constituciones es el desarrollo en la continuidad. El instrumento normal es la jurisprudencia; la reforma es un instrumento excepcional.

El objetivo de la jurisprudencia y de la reforma es concurrente. Las líneas de mutuo respeto son elásticas, como consecuencia de la discrecionalidad en que, con distinta medida, se mueven a la una y la otra. Por eso pueden entrar en colisión, y donde los procedimientos de reforma, con los cuales el legislador podría contener la expansión de la discrecionalidad judicial, son particularmente gravosos, el riesgo que corren las cortes es el de convertirse en una fuente incontrolada y de ser así rechazadas por la comunidad en la que operan" ${ }^{\prime \prime 3}$.

\section{Caso de estudio: El Caso D.C. vs. Heller como paradigma reciente del debate y la interacción de los métodos de interpretación "originalista" y "constitucionalismo viviente"}

Finalmente, pretendemos explicar de forma práctica, mediante el desarrollo de un análisis jurisprudencial, las diferencias entre los métodos aplicados a un caso real del sistema norteamericano. El reciente caso Heller (District of Columbia vs. Heller [No. 07-290] 478 f. 3d 370. 2008) relativo a la interpretación de una enmienda histórica de la constitución de Estados Unidos, en el contexto de un tema tan álgido como lo es el porte de armas para la sociedad norteamericana, es un excelente ejemplo del choque entre originalismo textual, intención original,

${ }^{83}$ ZAGReBelSKY (2006), pp. 1144-1145. 
significado original, no originalismo, constitucionalismo viviente, e incluso el uso de uno u otro método para defender agendas conservadoras o progresistas.

\subsection{Hechos y Problema Jurídico del Caso D.C. vs. Heller}

La controversia en el caso gira alrededor de una ley del Distrito de Columbia (Firearms Control Regulations Act), que prohíbe la posesión (tenencia y propiedad sin registro) de armas de fuego de corto alcance (handguns), prohíbe el porte de armas de fuego sin permiso, permitiendo a las autoridades policiales emitir licencias para períodos de un año. La ley adicionalmente requiere que los residentes mantengan esas armas de fuego "sin cargar, no ensambladas, $o$ bloqueadas por un seguro de gatillo o dispositivo similar"84 a menos que se encuentren en un lugar de comercio al que están destinadas a proteger o que estén siendo utilizadas para una actividad recreativa lícita. Dick Heller, un oficial de policía, autorizado para llevar un arma de fuego durante el servicio, solicitó un registro de un arma de fuego que quería mantener en casa. El distrito negó dicho registro. Heller presentó una demanda en la Corte Federal de Distrito del Distrito de Columbia, que buscaba que la ciudad levantara tal prohibición sobre las de armas de fuego, como el requisito de concesión de licencias, en la medida en que, a su parecer, violaba la Segunda Enmienda.

La ley en cuestión llevaba más de tres décadas de vigencia y era considerada por los activistas en materia de control de armas como ejemplar, igualmente era considerada como una de las más duras y restrictivas del país por tener el efecto práctico de una prohibición casi total al porte de armas ${ }^{85}$.

Heller, cuya demanda ante la Corte Federal del Distrito de Columbia Ilega posteriormente por vía de certiorati a la Corte Suprema de Justicia, sostiene que la ley es inconstitucional, pues viola las garantías establecidas en la Segunda Enmienda (1791), la cual provee:

Siendo necesaria una milicia bien ordenada para la seguridad de un Estado libre, el derecho del Pueblo a poseer y portar armas no será infringido. (A well regulated militia being necessary to the security of a free State, the right of the People to keep and bear arms shall not be infringed).

Sus contradictores, los abogados del Distrito de Columbia, sostenían que la enmienda, de forma escrita, expresa y textual, indica que el derecho a las armas solo existe con el fin de conformar una milicia para la defensa del Estado, no un derecho irrestricto de porte y uso individual.

${ }^{84}$ Firearms Control Regulations Act. 1975.

${ }^{85}$ EdWARd (1981), pp. 138-149. 
Visto el contenido de la ley y el texto de la enmienda, la pregunta jurídica es compleja: ¿Vulnera la legislación los derechos consagrados en la Segunda Enmienda? ¿La Segunda Enmienda contiene un derecho absoluto e individual para portar armas o un derecho colectivo y que solamente protege a las armas para participar y conformar una milicia para la defensa del Estado?

\subsection{Distintas interpretaciones de la Segunda Enmienda en Heller como ejemplos de los métodos de interpretación constitucional}

El caso es de especial interés, pues demuestra como dentro del mismo originalismo uno u otro submétodo puede arrojar resultados disímiles, rompiendo la preconcepción de que todos los métodos encontrarán el mismo "significado original" y también demostrando que el originalismo puede ser usado dentro de un mismo caso para defender distintas agendas judiciales ${ }^{86}$; una conservadora (en el sentido norteamericano del término, desde el punto de vista republicano), en cuanto a las armas, que las defiende a ultranza como un derecho absoluto y una línea de defensa de los ciudadanos contra toda amenaza e incluso contra el poder Federal) o una más progresiva, que busca su reducción y control ante los graves casos de intolerancia y violencia resultado de su proliferación (metodológicamente, en esta sección final, se citarán en los pies de páginas los extractos de la sentencia en su idioma original, en los que se desarrollan los métodos que se van comentando en la explicación).

¿Qué interpretaciones se le dieron a la Enmienda? La interpretación en la decisión (opinion) del juez Scalia, como los dos dissents de los jueces Stevens y Breyer, ejemplifican distintos métodos de interpretación:

\subsection{La Interpretación del juez Scalia: Intención original y significado original en la Segunda Enmienda}

Scalia, en su decisión, que fue apoyada por la mayoría ${ }^{87}$, aplicó un originalismo guiado por la intención original y el significado original, más que por el texto original (textualismo). Estos modelos buscan la intención de los redactores de la época y el significado de sus conceptos más que la aplicación estricta del texto histórico, pues consideran tanto al documento, pero también a la intención detrás de él, igualmente vinculantes. En su análisis, no todas las palabras textuales escritas en la constitución tienen el mismo valor jurídico (como lo tendrían en el modelo textualista) sino que el valor jurídico de la cláusula está dado por las indagaciones

\footnotetext{
${ }^{86}$ LUND (2009).

${ }^{87}$ Scalia, J., delivered the opinion of the Court, in which Roberts, C. J., and Kennedy, Thomas, and Alito, JJ., joined. Stevens, J., filed a dissenting opinion, in which Souter, Ginsburg, and Breyer, J., joined. Breyer, J., filed a dissenting opinion, in which Stevens, Souter, and Ginsburg, JJ., joined.
} 
históricas que se puedan hacer sobre las razones e intenciones originales de los redactores que esconde una enmienda con un texto complejo y el significado histórico de sus palabras clave. Expone Scalia en primer lugar que en la Segunda Enmienda, a pesar del hecho de hablarse de "el pueblo", término muy amplio, se entiende, por la forma en que están redactados todos los demás derechos en la constitución y en los documentos preparatorios de la época, que cuando los padres fundadores hablan de los "derechos del pueblo" están, en general, hablando de los derechos individuales, no derechos "colectivos", pues pretendían construir las enmiendas como protecciones al individuo. En segundo lugar, para la expresión "bear arms" (mantener o portar armas), se apoya de diccionarios de la épocapara entender la palabra bear (cargar) y encontrar que significa en su época, mantener o poseer de forma individual. Apoyado en el entendimiento de los Padres Fundadores de la noción "pueblo" y la finalidad que le daban a tal expresión (intención original), y del significado de la época de la expresión "cargar armas" (significado original) deriva un derecho individual a poseer armas de fuego ${ }^{88}$.

Igualmente, Scalia, ejerciendo el original meaning, estudia el significado para la época de la palabra "arms" buscándolo en diccionarios de 1773, descubriendo que significaba simplemente "armas", una expresión que incluía los medios de defensa de la gente común y que no se limitaba o refería a las usadas por la milicia o los ejércitos, como sí lo sería la expresión "armamento"

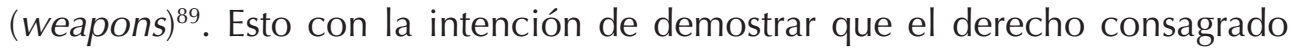
en la enmienda no tenía la intención de ser limitado a usos militares, sino ser

\footnotetext{
${ }^{88}$ From our review of founding-era sources, we conclude that this natural meaning was also the meaning that "bear arms" had in the 18th century. In numerous instances, "bear arms" was unambiguously used to refer to the carrying of weapons outside of an organized militia. The most prominent examples are those most relevant to the Second Amendment : Nine state constitutional provisions written in the 18th century or the first two decades of the 19th, which enshrined a right of citizens to "bear arms in defense of themselves and the state" or "bear arms in defense of himself and the state". 8 It is clear from those formulations that "bear arms" did not refer only to carrying a weapon in an organized military unit. Justice James Wilson interpreted the Pennsy/vania Constitution's arms-bearing right, for example, as a recognition of the natural right of defense "of one's person or house"-what he called the law of "self preservation". 2 Collected Works of James Wilson 1142, and n. x (K. Hall \& M. Hall eds. 2007) (citing Pa. Const., Art. IX, $\$ 21$ (1790)); see also T. Walker, Introduction to American Law 198 (1837) ("Thus the right of self-defence [is] guaranteed by the [Ohio] constitution"); see also id., at 157 (equating Second Amendment with that provision of the Ohio Constitution). That was also the interpretation of those state constitutional provisions adopted by pre-Civil War state courts. 9 These provisions demonstrate-again, in the most analogous linguistic context-that "bear arms" was not limited to the carrying of arms in a militia.

${ }^{89}$ Before addressing the verbs "keep" and "bear"," we interpret their object: "Arms". The 18th-century meaning is no different from the meaning today. The 1773 edition of Samuel Johnson's dictionary defined "arms" as "weapons of offence, or armour of defence". 1 Dictionary of the English Language 107 (4th ed.) (hereinafter Johnson). Timothy Cunningham's important 1771 legal dictionary defined "arms" as "any thing that a man wears for his defence, or takes into his hands, or useth in wrath to cast at or strike another". 1 A New and Complete Law Dictionary (1771); see also N. Webster, American Dictionary of the English Language (1828) (reprinted 1989) (hereinafter Webster) (similar).
} 
un derecho individual ejercible en todo tiempo y ocasión, para las armas que típicamente portan los individuos para su propia protección.

Además, investigandola historia de la enmienda misma, sostiene que su propósito era permitir a las personas su propia defensa, reconocer lo que los Estados federados ya habían reconocido en sus propias constituciones como un derecho individual, formalizar la práctica de la época en materia de armas y, de paso, permitirles estar listas para crear una milicia: es decir, que estuvieran, de forma individual, listos para defenderse de los invasores ingleses y prestos a proteger sus derechos.

Mediante documentos históricos Scalia justifica que el derecho a las armas siempre ha sido del "pueblo" (que precisamente, significa, de cada uno de los individuos), no solo del Ejército y que la verdadera intención de los redactores de la enmienda era reconocer el derecho de cada uno de los individuos a tener armas. A partir de la búsqueda de las intenciones de los redactores, Scalia identifica un derecho implícito a la legitima defensa dentro de un derecho explícito al porte de armas, que, si bien no es absoluto, pues pueden existir regulaciones (prohibírselas a los convictos, a personas con enfermedades mentales, etc.), no puede ser absolutamente limitado por los efectos de una ley como la cuestionada.

El anterior es un interesante caso de original intent y original meaning pues permite diferenciarlos plenamente del otro método originalista: el textualismo: Scalia en su explicación, considera las frases dentro de la enmienda, relativas a la milicia, como una prefactory clause, una cláusula introductoria, que solo cuenta de forma histórica, una de las tantas razones de la época para escribir la enmienda. Por otro lado, la parte vinculante de la enmienda, en sí misma, es lo escrito frente al derecho al porte de armas, lo que constituye la operative clause, cláusula operativa (o vinculante, eficaz) de la misma ${ }^{90}$.

The term was applied, then as now, to weapons that were not specifically designed for military use and were not employed in a military capacity. For instance, Cunningham's legal dictionary gave as an example of usage: "Servants and labourers shall use bows and arrows on Sundays, \&c. and not bear other arms". See also, e.g., An Act for the trial of Negroes, 1797 Del. Laws Ch. XLIII, \&6, p. 104, in 1 First Laws of the State of Delaware 102, 104 (J. Cushing ed. 1981 (pt. 1)); see generally State v. Duke, 42 Tex. 455, 458 (1874) (citing decisions of state courts construing "arms"). Although one founding-era thesaurus limited "arms" (as opposed to "weapons") to "instruments of offence generally made use of in war," even that source stated that all firearms constituted "arms". $1 \mathrm{~J}$. Trusler, The Distinction Between Words Esteemed Synonymous in the English Language37 (1794) (emphasis added).

90 1. The Second Amendment protects an individual right to possess a firearm unconnected with service in a militia, and to use that arm for traditionally lawful purposes, such as self-defense within the home. Pp. 2-53.

(a) The Amendment's prefatory clause announces a purpose, but does not limit or expand the scope of the second part, the operative clause. The operative clause's text and history demonstrate that it connotes an individual right to keep and bear arms. pp. 2-22.

(b) The prefatory clause comports with the Court's interpretation of the operative clause. The "militia" comprised all males physically capable of acting in concert for the common defense. The Antifederalists feared that the Federal Government would disarm the people in order to disable this citizens' militia, 


\subsection{La Interpretación del juez Stevens: originalismo textual en la Segunda Enmienda}

Si bien la opinión de Scalia constituye el derecho vigente (binding precedent) y su conclusión es que las restricciones impuestas por la ley del D.C. violan la segunda enmienda al limitar de forma grave el derecho individual al porte de armas, la opinión disidente del juez Stevens debe ser también analizada pues constituye otro uso del originalismo, que propone un resultado más progresista (apoyando la limitación de la ley en cuestión al porte de armas) mediante la aplicación de otro método originalista, el textualismo.

Stevens en su dissent es un originalista textual, dándole valor jurídico pleno a cada una de las expresiones históricas y considerando intocable la integridad del texto: considera que el texto inequívocamente indica que se aprobó la segunda enmienda para permitirle al pueblo (en conjunto) armarse para mantener una milicia, y por lo tanto no existe el derecho irrestricto de usar las armas para fines no militares, como la caza o la defensa. Según el texto, desde su lectura como documento histórico explícito, lo que existe es una protección a la milicia a mantener esas armas, no un derecho de cada individuo:

When each word in the text is given full effect, the Amendment is most naturally read to secure to the people a right to use and possess arms in conjunction with service in a well-regulated militia. So far as appears, no more than that was contemplated by its drafters or is encompassed within its terms. Even if the meaning of the text were genuinely susceptible to more than one interpretation, the burden would remain on those advocating a departure from the purpose identified in the preamble and from settled law to come forward with persuasive new arguments or evidence. The textual analysis offered by respondent and embraced by the Court falls far short of sustaining that heavy burden.14 And the Court's emphatic reliance on the claim "that the Second Amendment ... codified a pre-existing right," ante, at 19, is of course beside the point because the right to keep and bear arms for service in a state militia was also a pre-existing right (Traducción libre en el pie de página) ${ }^{91}$.

enabling a politicized standing army or a select militia to rule. The response was to deny Congress power to abridge the ancient right of individuals to keep and bear arms, so that the ideal of a citizens' militia would be preserved. pp. 22-28.

(c) The Court's interpretation is confirmed by analogous arms-bearing rights in state constitutions that preceded and immediately followed the Second Amendment. pp. 28-30.

(d) The Second Amendment's drafting history, while of dubious interpretive worth, reveals three state Second Amendment proposals that unequivocally referred to an individual right to bear arms. pp. 30-32.

${ }^{91}$ Traducción Libre: Cuando a cada palabra del texto se le da pleno efecto, la enmienda se lee de manera más natural hacia asegurar el derecho de la gente a usar y poseer armas en conjunto con el servicio a 
En el anterior apartado de su dissent, Stevens demuestra los principales elementos del textualismo: procurar la eficacia de todo el texto escrito histórico, dándole valor jurídico a cada palabra: bajo tal premisa, las expresiones relativas a la milicia no pueden ser ignoradas y si gramaticalmente están unidas al derecho al porte de armas, tales palabras no pueden ser consideradas como introductorias: desde el textualismo, la cláusula debe leerse y aplicarse completamente, dándole la lectura gramatical más acertada posible al texto original ${ }^{92}$, siendo la constitución escrita la máxima law of the land.

Según Stevens, esa lectura no es otra que reconocer que el derecho a las armas no es individual, no es absoluto y no está justificado por fuera de los fines de la milicia, dictaminando así que la constitución federal no establece un derecho individual inviolable al porte de armas y que por ello, la legislación de D.C. no vulnera la enmienda y por lo tanto puede seguir teniendo efecto. Para Stevens, como para otros críticos del originalismo de Scalia, el originalismo aplicado por este último es engañoso ${ }^{93}$, pues usa argumentos de conveniencia y lecturas propias de la historia, en cambio, el texto original es inmutable y debe ser aplicado palabra por palabra en toda su supuesta claridad.

\subsection{El dissent del Juez Breyer: Una propuesta de ponderación desde el constitucionalismo viviente}

Finalmente, el dissent del juez Breyer es especialmente interesante pues parte de un mecanismo (device) originalista para proponer una posición de constitucionalismo vivo ${ }^{94}$. Para Breyer, la Segunda Enmienda debe ser analizada más allá de si explicita o no un derecho a la milicia o a la defensa propia, de carácter individual o colectivo, porque, precisamente, ambos derechos son coexistentes y no jerarquizables, estén histórica y taxativamente expresos en la cláusula. Para Breyer, la regulación del distrito de Columbia y su constitucionalidad frente a la Segunda Enmienda no dependen de la existencia de un derecho histórico y absoluto, sino de un equilibrio de conveniencias y finalidades públicas de la ley

una milicia bien regulada. Hasta allí, no más que eso fue contemplado por los redactores o se incluyó dentro de sus términos. Incluso si el significado del texto fuera genuinamente susceptible de más de una interpretación, la carga persistiría en aquellos abogando a separarse del propósito identificado en el propósito y de normas decantadas, de adelantar nuevos argumentos persuasivos o evidencia. El análisis textual ofrecido por el demandado y que fue aceptado por la Corte, no alcanza a responder esa pesada carga. (14) Y, la enfática dependencia de la Corte en el argumento de que "la segunda enmienda codifica un derecho preexistente", previamente expuesta en el parágrafo 19, se encuentra naturalmente fuera del punto, porque el derecho para tener y portar armas para una milicia también es un derecho preexistente".

92 VOLOKH (2014), pp. 729-1171.

93 Merkel (2009).

${ }^{94}$ Schragger (2008), p. 283. 
en cuestión, vistas desde su justificación para limitar derechos en un contexto social contemporáneo y determinado como es la proliferación de armas en la actual sociedad norteamericana:

Would simply adopt such an interest-balancing inquiry explicitly. The fact that important interests lie on both sides of the constitutional equation suggests that review of gun-control regulation is not a context in which a court should effectively presume either constitutionality (as in rationalbasis review) or unconstitutionality (as in strict scrutiny). Rather, "where a law significantly implicates competing constitutionally protected interests in complex ways," the Court generally asks whether the statute burdens a protected interest in a way or to an extent that is out of proportion to the statute's salutary effects upon other important governmental interests. See Nixon v. Shrink Missouri Government PAC, 528 U. S. 377, 402 (2000) (Breyer, J., concurring). (Traducción libre en el pie de página) ${ }^{95}$.

El tipo de fallo que propone Breyer es, entonces, claramente no originalista, basado en el constitucionalismo viviente: por medio del estudio de las finalidades de la ley, de las medidas gubernamentales al adoptarla y de la justificación para declararla y su comparación con la urgencia y necesidad de la medida, trata de proponer un escrutinio de la misma apoyado en las sentencias precedentes en material de acción gubernamental que limite derechos individuales. Breyer hace un Ilamado a aplicar estos test de escrutinio (strict scrutiny, interest-balancing scrutiny) y a considerar los hechos actuales del Estado donde se aplica la norma para ver si el legislador tenía o no un interés y propósito legítimos ${ }^{96}$, debidamente justificado al construir esas limitaciones (rational basis ${ }^{97}$ ): de existir suficiente justificación, la ley sería constitucional.

\section{Consideraciones Finales}

El caso anteriormente desarrollado ilustra los distintos resultados a los que puede llegar la interpretación de un mismo pasaje constitucional bajo distintos

\footnotetext{
${ }^{95}$ Traducción Libre: “Debería simplemente adaptarse una indagación de balance de intereses de manera explícita. El hecho de que intereses importantes existen en ambos lados de esta ecuación constitucional, sugiere que la revisión de la regulación sobre el control de armas no se da en un contexto en que una Corte deba efectivamente presumir ni la constitucionalidad (como en test de control racional) o inconstitucionalidad (como en el test estricto). Por el contrario, cuando una ley significativamente implica a intereses constitucionalmente protegidos que compiten entre sí en modos complejos, la Corte generalmente se pregunta si el estatuto afecta tales intereses protegidos en una forma o extensión que sea desproporcionada para los efectos deseables de tal estatuto sobre intereses gubernamentales importantes. Ver Nixon v. Shrink Missouri Government PAC, 528 U. S. 377, 402 (2000) (Breyer, J., Voto concurrente)".

${ }^{96}$ Heller vs. Doe, 509 U. S. 312, 320 (1993).

${ }^{97}$ United States vs. Virginia, 518 U. S. 515, 531-534 (1996).
} 
métodos, tanto originalistas como no originalistas. El cúmulo de métodos empleados y los disímiles resultados, que a su vez representan filosofías jurídicas sobre la constitución y agendas políticas distintas, pueden ser resumidos de la siguiente manera en una tabla comparativa:

\begin{tabular}{|c|c|}
\hline \multicolumn{2}{|c|}{$\begin{array}{l}\text { El Caso D.C. vs. Heller (2008) como paradigma } \\
\text { reciente de los métodos de interpretación }\end{array}$} \\
\hline Ley Objeto de control constitucional: & $\begin{array}{c}\text { Principal Norma } \\
\text { Constitucional involucrada }\end{array}$ \\
\hline $\begin{array}{l}\text { Firearms Control Regulations Act. } 1975 \\
\text { - } \quad \text { Prohibición a la posesión de armas sin } \\
\text { registro } \\
\text { - } \quad \text { Prohibición al porte de armas sin permiso } \\
\text { - } \quad \text { eas armas en lugares no comerciales deben } \\
\text { mecánico. }\end{array}$ & $\begin{array}{l}\text { Segunda Enmienda: Siendo necesaria una } \\
\text { milicia bien ordenada para la seguridad de } \\
\text { un Estado libre, el derecho del Pueblo a po- } \\
\text { seer y portar armas no será infringido. }\end{array}$ \\
\hline \multicolumn{2}{|c|}{$\begin{array}{l}\text { Procedimientos y Resultados de la interpretación } \\
\text { constitucional según distintos métodos: }\end{array}$} \\
\hline Método de interpretación & Procedimientos y Resultados \\
\hline $\begin{array}{l}\text { Significado Original (Interpretación del juez } \\
\text { Scalia en la Opinión mayoritaria) }\end{array}$ & $\begin{array}{l}\text { Significados de expresiones clave como } \\
\text { pueblo y "bear arms" } \\
\text { - Pueblo: se usaba en la época para de- } \\
\text { finir un conjunto de individuos, no a } \\
\text { la nación, por lo que se está hablando } \\
\text { de un derecho individual. Así ocurre en } \\
\text { otras enmiendas. } \\
\text { - "Bear Arms": En los diccionarios de la } \\
\text { época, la expresión "arms" se refiere a } \\
\text { las armas de uso habitual de los indivi- } \\
\text { duos, no a los artefactos de guerra de la } \\
\text { milicia. } \\
\text { Conclusión: la enmienda se refiere a un } \\
\text { derecho individual a portar armas que } \\
\text { no debe ser infringido. }\end{array}$ \\
\hline $\begin{array}{l}\text { Intencion Original (Interpretación del Juez } \\
\text { Scalia en la Opinión mayoritaria) }\end{array}$ & $\begin{array}{l}\text { Identificar la intención de la Enmienda en } \\
\text { documentos históricos: } \\
\text { - La Enmienda fue escrita para garantizar } \\
\text { un derecho individual y la mención de la } \\
\text { Milicia es solo una cláusula introductoria } \\
\text { y una de las muchas razones por las cua- } \\
\text { les se escribió la enmienda. Los Framers } \\
\text { querían hacer expreso a nivel federal un } \\
\text { derecho ya reconocido por constituciones } \\
\text { locales y que se ejercía de forma regular. } \\
\text { - Conclusión: la enmienda se refiere a un } \\
\text { derecho individual a portar armas que } \\
\text { no debe ser infringido. }\end{array}$ \\
\hline
\end{tabular}




\begin{tabular}{|l|l|}
\hline $\begin{array}{l}\text { Textualismo: Dissent e Interpretación del juez } \\
\text { Stevens }\end{array}$ & $\begin{array}{l}\text { La enmienda debe ser leída de forma } \\
\text { gramatical y todas sus palabras deben tener } \\
\text { valor jurídico. } \\
\text { Las expresiones a la milicia están taxa- } \\
\text { tivamente escritas y gramaticalmente } \\
\text { ligadas al derecho incluido en la en- } \\
\text { mienda, que necesariamente es enton- } \\
\text { ces un derecho del pueblo a armarse } \\
\text { pero con fines de formar milicia: solo } \\
\text { ese tipo de derecho es protegido. } \\
\text { Conclusión: La Segunda Enmienda no } \\
\text { protege un derecho individual inviola- } \\
\text { ble, sino un derecho colectivo a formar } \\
\text { milicia. La legislación que limita el por- } \\
\text { te de armas es válida. }\end{array}$ \\
\hline $\begin{array}{l}\text { Constitucionalismo Viviente: Niveles de escru- } \\
\text { tinio y equilibrio de intereses }\end{array}$ & $\begin{array}{l}\text { Más allá de la historia de la enmienda, en } \\
\text { un argumento de practicidad, se deben } \\
\text { aplicar los test de escrutinio (strict scrutiny, } \\
\text { interest-balancing scrutiny, desarrollados } \\
\text { por jurisprudencia previa sobre medidas } \\
\text { Estatales que limitan derechos civiles) y } \\
\text { considerar los hechos actuales del Esta- } \\
\text { do donde se aplica la norma para ver si el } \\
\text { legislador tenía o no un interés y propósito } \\
\text { legítimo y debidamente justificado al con- } \\
\text { struir esas limitaciones (rational basis): de } \\
\text { existir suficiente justificación, la ley será } \\
\text { constitucional. }\end{array}$ \\
\hline
\end{tabular}

Tabla 2: Elaborada por los autores.

Tras el estudio de las principales doctrinas en materia de interpretación, sus fundamentos jurídico-políticos y el ejercicio de identificación de métodos de interpretación en una decisión contemporánea, en este apartado final, corresponde puntualizar y reiterar el enfoque esencial de cada uno de los métodos derivados del originalismo y el no-originalismo ofreciendo una formulación sencilla y definitiva de cada uno de ellos:

En el marco del originalismo, que ya hemos definido como aquella doctrina que considera que el significado de la Constitución no cambia ni evoluciona con el tiempo, sino que el texto constitucional es a la vez fijo y cognoscible, que no debe verse influenciado por la percepción del juez de los sucesos de la realidad actual y que como constitución deriva su validez del pacto asambleísta y no de su adaptabilidad a la modernidad, encontramos, en primer lugar, el método del textualismo: Encaminado a dar valor legal a todas y cada una de las palabras escritas en la constitución, en tanto son taxativas y no pueden ser modificadas, enmendadas o adicionadas por interpretaciones de la realidad contemporánea. 
El textualista leerá la constitución palabra por palabra y procederá aplicándola rigurosamente, considerando el "texto" y el significado habitual de las palabras como lo verdaderamente original y vinculante por ser el producto final y escrito taxativamente del trabajo de los Padres Fundadores.

Por otro lado, encontramos el método del significado original (original meaning), que, como el textualismo, parte de la realidad escrita de la constitución, pero va más allá de considerar el texto plano como vinculante solo por estar en ella. En el método del significado original, se hace una indagación histórica y gramatical del significado de las palabras, para de allí derivar las consecuencias actuales de las normas constitucionales. En este método, se acude a diccionarios históricos o a trabajos preparatorios para encontrar el "significado original" de las expresiones en la época en que fueron redactadas. Se busca el significado que los textos constitucionales hubiesen tenido para sus redactores y lectores al momento de su creación, buscando encontrar el significado por el cual fueron redactados de esa manera y no el significado que la realidad contemporánea les quiera dar ${ }^{98}$.

En esa búsqueda por los valores que trataban de establecer los redactores originales de la constitución, otro método originalista menos apegado al texto pero alimentado por las mismas fuentes complementarias toma relevancia: el método de la intención original: para este método, ante la interpretación de una determinada norma constitucional, se deben indagar todas las fuentes históricas posibles que describan cuál era la intención de los padres fundadores en esa materia, para así iluminar la interpretación del texto, que podría no aplicarse textualmente, pero debería aplicarse según la intención de sus redactores que pudo o no quedar plasmada directamente en el mismo, pero que podría ser consultada, por ejemplo, en su correspondencia, en sus obras políticas, en sus debates en la asamblea constituyente, etc. ${ }^{99}$. Este método es objeto de fuerte debate pues también puede llevar a restricciones en la aplicación de la constitución frente a temas más allá de sus propósitos originales, como ocurrió en los hoy superados, Slaughter-house cases, donde a pesar de reconocer que para interpretar la constitución era necesario indagar sobre los propósitos y motivos por los cuales las enmiendas fueron diseñadas, las garantías mencionadas en ellas no pueden ser otorgadas a derechos que no contemplaran quienes las diseñaron: En aquellos casos, no se aplicaron las protecciones de igualdad ante la ley incluidos en la enmienda catorce a quienes la invocaban, porque el problema jurídico de la salubridad y los monopolios de mataderos no corres-

\footnotetext{
${ }^{98}$ BARNETT (2013).

${ }^{99}$ KIRBY (2000).
} 
pondía con la intención original de la enmienda, que era resolver el problema de la esclavitud ${ }^{100}$.

Finalmente, el no originalismo, la doctrina opuesta, adopta los postulados del constitucionalismo viviente, que busca promover una visión de la constitución que es cambiante y adaptativa a las realidades sociales, a los cambios históricos, a las nuevas necesidades de la sociedad.

En ese contexto, el no originalismo no considera los elementos originales de la constitución como inamovibles, sino como el punto de partida para construir jurisprudencialmente nuevas realidades constitucionales que superen los límites escritos de una constitución que tal vez ya no responda a los problemas actuales. En ese contexto, el no originalismo se vale de la actividad judicial para construir test acerca de la adecuación de las normas constitucionales a la realidad, indagar por los efectos de las decisiones judiciales en la economía, indagar sobre las necesidades de la sociedad y las respuestas que requiere y que pueden o no estar taxativamente escritos en la constitución y construir jurisprudencialmente, una constitución de precedente, a encontrar en las sentencias, donde existen nuevos derechos, nuevos límites al Estado, nuevos métodos de sustanciar las decisiones judiciales y de resolver los problemas constitucionales más allá de los límites escritos de la constitución y su texto original.

\section{BibliografíA CITADA}

ACKerman, Bruce (2011): La Constitución viviente (Marcial Pons), Tomo I.

Aldunate Lizana, Eduardo (2010): “Aproximación conceptual y crítica al neoconstitucionalismo", en: Revista de Derecho (Año 23, № 1), pp.79-102.

AlEXY, Robert (2003): "On balancing and subsumption. A structural comparison", en : Ratio Juris (Año 16, No 4), pp. 433-449.

AlEXY, Robert (2009): A theory of constitutional rights. (Oxford University Press, USA).

AmAR, Akhil Reed (2012): "American Constitutionalism-Written, Unwritten, and Living", en: Harv. L. Rev. F., pp. 126-195.

BarKow, Rachel (2002): "More supreme than court? The fall of the political question doctrine and the rise of judicial supremacy", en: Columbia Law Review, pp. 237-336.

BARNETT, Randy E. (2013): Restoring the lost constitution: The presumption of liberty. (Princeton University Press).

100 Newsom (2000), pp. 643-744. 
BésA, Alice (2006): "Le juge et le «dessein intelligent» aux États-Unis", en: Esprit ( $\left.N^{\circ} 6\right)$, p. 181.

BIRD, K. (2001): "L'impossible réglementation des propos à caractère raciste aux États-unis", en: Revue française de droit constitutionnel ( $\left.N^{\circ} 2\right)$, pp. 265-287.

BReYer, Stephen (2005): Pour une démocratie active. (Odile Jacob).

Burgess, Susan (2013): The Founding Fathers, Pop Culture, and Constitutional Law: Who's Your Daddy? (Ashgate Publishing, Ltd).

Carbonell Sánchez, M. (2003): Neoconstitucionalismo. (Madrid, Trotta).

Charles, Patrick J. (2010): "Originalism, John Marshall, and the Necessary and Proper Clause: Resurrecting the Jurisprudence of Alexander Addison", en: Cleveland State Law Review (Año 58), p. 529.

Chemerinsky, Erwin (2006): Constitutional law. Principles and policies (Introduction to law series), (New York, Aspen Publishers).

Cross, Frank B. (2012): "Originalism-the forgotten years", en: Const. Comment (Año 28), p. 37.

Cruz, David B. (2000): "The Sexual Freedom Cases? Contraception, Abortion, Abstinence, and the Constitution", en: Harvard Civil Rights-Civil Liberties Law Review (Año 35, № 2).

Dubols, Ellen Carol (1987): "Outgrowing the Compact of the Fathers: Equal Rights, Woman Suffrage, and the United States Constitution, 1820-1878", en: The Journal of American History (Vol. I), pp. 836-862.

EIDELBERG, Paul (1986): The philosophy of the American Constitution: A reinterpretation of the intentions of the founding fathers. (University Press of America).

EsQUIROL, Jorge L. (2008): "The failed law of Latin America", en: American Journal of Comparative Law (Año 56, Nº 1), pp. 75-124.

Fallon Jr., Richard H. (2011): "Are Originalist Constitutional Theories Principled, or Are They Rationalizations for Conservatism", en: Harv. JL \& Pub. Policy (Año 34), p. 5.

García de Enterría, Eduardo (1985): La Constitución como norma y el Tribunal Constitucional. (Editorial Cívitas, Madrid).

Gargarella, Roberto (1997): "Recientes reformas constitucionales en América Latina: una primera aproximación". En: Desarrollo económico (Vol. I), pp. 971-990.

Goldstone, Lawrence (2010): The Activist: John Marshall, Marbury V. Madison, and the Myth of Judicial Review. (Bloomsbury Publishing USA).

GoldswORTHY, Jeffrey (1997): "Originalism in Constitutional Interpretation", en: Federal Law Review (Año 25, № 1). 
GragliA, Lino A. (1995): “United States v. Lopez: Judicial Review Under the Commerce Clause", en: Tex. L. Rev. (Año 74), p. 719.

HÄвеRLE, Peter (2002): "La Constitución como cultura", en: Anuario iberoamericano de justicia constitucional ( $\left.\mathrm{N}^{\circ} 6\right), 177-198$.

Henkin, Louis (1976): Is There a "Political Question" Doctrine?, en: The Yale Law Journal (Año 85, No 5), pp. 597-625.

Hesse, Konrad (1992): "Escritos de derecho constitucional" (Traducc. Pedro Cruz Villalón, Miguel Azpitarte. Centro de estudios constitucionales).

HUYLER, Jerome (1995): Locke in America: The Moral Philosophy of the Founding Era. (Univ. Press of Kansas).

JONES, Edward D. (1981): "The District of Columbia's" Firearms Control Regulations Act of 1975": The Toughest Handgun Control Law in the United States-Or Is It?.", en: The Annals of the American Academy of Political and Social Science (Año 455, № 1), pp. 138-149.

Kannar, George (1990): "The Constitutional Catechism of Antonin Scalia", en: The Yale Law Journal (Año 99, № 6), pp. 1297-1357.

KIRBY, Michael (2000) "Constitutional interpretation and original intent: A form of ancestor worship". En: Melb. UL Rev. (Año 24, № 1).

LessiG, L. (1992): "Fidelity in translation" en: Texas Law Review (Vol. 71), p. 1165.

Library of Congress. The Thomas Jefferson Papers Series 1. Thomas Jefferson to Samuel Kercheval, July 12, 1816 General Correspondence, pp. 1651-1827.

LLoyD, G. (2013): "Marshall v. Madison: The Supreme Court and Original Intent, 1803-35", en: Criminal Justice Ethics, (Año 32, № 1), pp. 20-50.

Lund, Nelson (2009): "The Second Amendment, Heller, and Originalist Jurisprudence.", en: UCLA Law Review (Vol. I).

MARION, David E. (2005): "Judicial Faithfulness or Wandering Indulgence-Original Intentions and the History of Marbury v. Madison.", en: Ala. L. Rev. (Año 57), p. 1041.

Mcconnelt, M. (1997): "The importance of Humility in Judicial Review: A comment on Ronald Dworkin's "Moral Reading" of the Constitution", en: Fordham Law Review (Vol 65), p. 1269.

Mccinnis, John (2007): "Original Interpretative Principles as the Core of Originalism.", en: Constitutional Commentary.

MEDINA, Diego (2004): Teoría impura del derecho: la transformación de la cultura jurídica latinoamericana. (Legis). 
Merkel, William G. (2009): "The District of Columbia v. Heller and Antonin Scalia's Perverse Sense of Originalism.", en: Lewis \& Clark Law Review (Año13, No 2).

MilLeR, Arthur Selwyn (1979): Social change and fundamental law: America's evolving Constitution, Westport, Conn.: Greenwood Press ( $\left.\mathrm{N}^{\circ} 41\right)$.

Natelson, Robert G. (2002): "Enumerated Powers of States, The", en: Nevada Law Journal ( $\left.\mathrm{N}^{\circ} 3\right)$, p. 469.

Newsom, Kevin Christopher (2000): "Setting Incorporationism Straight: A Reinterpretation of the Slaughter-House Cases", en: Yale Law Journal, pp. 643-744.

O'NEILL, Johnathan (2002): "Marbury v Madison at 200: Revisionist Scholarship and the Legitimacy of American Judicial Review", en: The Modern Law Review (Año 65, № 5), pp. 792-802.

O'NeILL, Johnathan (2005): Originalism in American Law and Politics: A Constitutional History. (JHU Press).

Pactet, Pierre (1992): «La loi, permanence et changements », en Mélanges René Chapus (Paris, Montchrestien).

Pactet, Pierre (1998): «Á propos de la marge de liberté du Conseil constitutionnel », en Mélanges Jacques. Robert (Paris, Montchrestien).

PASTOR, Roberto Viciano (2011): "El nuevo constitucionalismo latinoamericano: fundamentos para una construcción doctrinal", en: Revista general de derecho público comparado (No 9), pp. 1-24.

Pfersmann, Otto (2009) : «De l'impossibilité du changement de sens de la constitution ». (Mélanges P. Pactet).

Posner, Richard (2010): How Judges Think (Harvard University Press).

RichardS, David A. J. (1978): "Sexual Autonomy and the Constitutional Right to Privacy: A Case Study in Human Rights and the Unwritten Constitution", en: Hastings Law Journal (Vol. 30), p. 957.

SAGER, Lawrence (2007): Juez y Democracia: Una teoría de la práctica Constitucional Norteamericana (Marcial Pons).

SANDAlow, Terrance (1981): "Constitutional Interpretation", en: Michigan Law Review, pp. 1033-1072.

Sandalow, Terrance (1977): "Judicial Protection of Minorities", en: Michigan Law Review, pp. 1162-1195.

Schmitt, Carl (2008): Théorie de la Constitution. Deroche, Lyliane (Trad.). Presses universitaires de France. 
SchragGer, Richard (2008): "The Last Progressive: Justice Breyer, Heller, and 'Judicial Judgment', ", en: Syracuse L. Rev. (No 59), p. 283.

SIMON, Larry G. (1985): "The Authority of the Framers of the Constitution: Can Originalist Interpretation Be Justified? ", en: California Law Review (1985), pp. 1482-1539.

Strauss David A. (1996): "Common law constitutional interpretation". en: The University of Chicago Law Review, pp. 877-935.

Strauss, David A. (2010): "Do We Have a Living Constitution?", en: Drake Law Review (No 59), p. 973.

StRauss, David A. (2010): "The living constitution". (Oxford University Press).

U.S. Firearms Control Regulations Act. 1975.

U.S. Supreme Court. Brown vs. Board of Education of Topeka, 347 U.S. 483 (1954).

U.S. Supreme Court. Heart of Atlanta Motel Inc. vs. United States, 379 U.S. 241 (1964).

U.S. Supreme Court. Heller vs. Doe, 509 U. S. 312, 320 (1993).

U.S. Supreme Court. Marbury vs. Madison, 5 U.S. 137 (1803).

U.S. Supreme Court. Meyer vs. Nebraska, 262 U.S. 390 (1923).

U.S. Supreme Court. United States vs. Virginia, 518 U. S. 515, pp. 531-534 (1996).

U.S. Judiciary Act of 1789, § 13.

U.S. Supreme Court. Plessy vs. Ferguson, 163 U.S. 537 (1896). 